\title{
Pseudomonas aeruginosa endocarditis in drug addicts
}

\author{
Gordon Archer, M.D. \\ F. Robert Fekety, M.D. \\ Ronald Supena, M.D. \\ Ann Arbor and Eloise, Mich.
}

Bacterial endocarditis is a serious medical complication of heroin addiction and should be suspected in any addict with a fever and positive blood cultures. However, gram-negative bacteria, and particularly Pseudomonas aeruginosa, are uncommon causes of bacterial endocarditis and their presence in a blood culture may be dismissed as a contaminant or as originating from another site. Therefore, to call attention to the problem and its clinical features, we are reporting six recently observed cases of $P$. aeruginosa endocarditis in heroin addicts.

\section{Materials and methods}

All patients were seen at one of the University of Michigan Affiliated Hospitals between Nov. 1970 and April 1972. The criteria for the diagnosis of Pseudomonas endocarditis were: (1) multiple blood cultures positive for the organism, (2) absence of another source of bacteremia, and (3) either a significant cardiac murmur or a specimen of the valve which harbored the organism as determined by culture or microscopic examination. $P$. aeruginosa was identified from blood cultures using standard laboratory procedures. ${ }^{1}$ In vitro antibiotic susceptibility studies were performed with standard Kirby-Bauer disc techniques using a 50 microgram carbenicillin disc. ${ }^{2}$ Serial broth dilution susceptibility studies were performed in Mueller-Hinton broth using a microtiter plate method. ${ }^{3}$

From the Department of Internal Medicine, Section of Infectious Dis. eases, University of Michigan Medical Center, Ann Arbor, and the Wayne County General Hospital, Eloise, Mich.

Received for publication Feb. 6,1974.

Reprint requests to: Dr. Gordon Archer, Veterans Administration Hospital, Ann Arbor, Mich. 48105.
General characteristics. All of the patients were heroin addicts. There were five men and one woman. The mean age was 35.7 years, and all were black.

Clinical features. The duration of symptoms before the onset of therapy varied from several days to six months. All of the patients were febrile, and five of the six had splenomegaly. In five patients, the infection involved the right side of the heart, the sixth patient having endocarditis of a prosthetic aortic valve. Four of the infections involved previously normal valves and two were on prosthetic valves. Four of the five patients with tricuspid valve endocarditis had pulmonary emboli. All four patients were symptomatic with chest pain and shortness of breath, and three had audible pleural rubs. A murmur referable to the involved valve was heard in every instance, but in two patients a faint systolic murmur suggestive of tricuspid insufficiency was appreciated only in restrospect after the diagnosis had been firmly established. Evidence of peripheral emboli such as petechiae, splinter hemorrhages, Roth spots, and hematuria was found in only two of the six cases (Table I). One of the two was a patient with aortic valve involvement, and the other had concomitant bacteremia with Staphylococcus aureus. Three patients remained remarkably well clinically during several months of continued Pseudomonas bacteremia. None of the patients developed hypotension during their Pseudomonas sepsis. Two patients were found to be using intravenous drugs while in the hospital, and in two others this was suspected.

\section{Results}

Blood cultures. Multiple blood cultures were positive in all cases, but in three instances en- 
Table I. Clinical features of six patients with Pseudomonas endocarditis

\begin{tabular}{|c|c|c|c|c|c|c|c|c|c|c|}
\hline Patient & Fever & Murmur & $\begin{array}{l}\text { Spleno- } \\
\text { megaly }\end{array}$ & $\begin{array}{l}\text { Splinter } \\
\text { hemor- } \\
\text {-rhages }\end{array}$ & Clubbing & $\begin{array}{c}\text { Skin } \\
\text { stigmata of } \\
\text { intravenous } \\
\text { drug } \\
\text { abuse }\end{array}$ & $\begin{array}{l}\text { Pleural } \\
\text { rub }\end{array}$ & Hematuria & Initial WBC & $\begin{array}{l}\text { Radiological } \\
\text { evidence of } \\
\text { cavitating } \\
\text { infiltrates }\end{array}$ \\
\hline 1 & + & + & + & + & - & + & - & + & $\begin{array}{c}17,400 \\
\text { left shift. }\end{array}$ & - \\
\hline 2 & + & + & + & - & - & + & + & - & $\begin{array}{r}14,000 \\
\text { left shift }\end{array}$ & + \\
\hline 3 & + & + & + & - & - & + & + & - & $\begin{array}{c}9,400 \\
\text { normal } \\
\text { differential }\end{array}$ & + \\
\hline 4 & + & + & + & - & + & + & - & - & $\begin{array}{c}9,800 \\
\text { normal } \\
\text { differential }\end{array}$ & + \\
\hline 5 & + & + & + & - & + & + & - & - & $\begin{array}{c}7,200 \\
\text { left shift }\end{array}$ & - \\
\hline 6 & + & + & - & - & - & + & + & + & $\begin{array}{c}10,200 \\
\text { left shift }\end{array}$ & + \\
\hline Total & $6 / 6$ & $6 / 6$ & $5 / 6$ & $1 / 6$ & $2 / 6$ & $6 / 6$ & $3 / 6$ & $2 / 6$ & $2 / 6$ high & $4 / 6$ \\
\hline
\end{tabular}

Table II. Blood cultures in six patients with Pseudomonas endocarditis

\begin{tabular}{|c|c|c|}
\hline Patient & Organisms at admission & No. cultures positive \\
\hline 1 & P. aeruginosa & $\begin{array}{l}6 / 8 \text { on Day } 1 * \text { (Pseudo) } \\
4 / 4 \text { over next } 2 \text { weeks (Pseudo) }\end{array}$ \\
\hline 2 & P. aeruginosa & $\begin{array}{l}6 / 6 \text { on Day } 1 \text { (PBeudo) } \\
\text { All negative during therapy } \\
2 / 13 \text { after therapy, before discharge } \\
\text { (Pseudo) }\end{array}$ \\
\hline 3 & $\begin{array}{l}\text { Group A beta-hemolytic } \\
\text { streptocorcus }\end{array}$ & $\begin{array}{l}4 / 4 \text { on Day } 1 \text { (Gr A Strep) } \\
8 / 8 \text { on Day } 5 \text { (Pseudo) } \\
\text { All positive until surgery (Pseudo) } \\
\text { Negative afterwards }\end{array}$ \\
\hline 4 & S. fecalis & $\begin{array}{l}4 / 4 \text { on Day } 1 \text { (S. fecalis) } \\
1 / 4 \text { on Day } 13 \text { (Pseudo) } \\
\text { All positive over next } 8 \text { months (Pseudo) }\end{array}$ \\
\hline 5 & P. aeruginosa and S. viridans & $\begin{array}{l}4 / 4 \text { on Day } 1 \text { (Pseudo and S. viridans) } \\
5 / 5 \text { on Day } 12 \text { (Pseudo) } \\
\text { Negative for } 3 \text { months with relapse (Pseudo) } \\
6 / 6 \text { Day } 1 \text { (S. aureus and Pseudo) }\end{array}$ \\
\hline
\end{tabular}

${ }^{*}$ Hospital day when positive blood cultures were drawn.

docarditis was not initially suspected as the source of bacteremia. In only one patient was Pseudomonas the first and only organism isolated from blood cultures. Four patients had other organisms grown from blood culture on admission to the hospital, and Pseudomonas was eventually recovered and persisted after the initially recognized pathogens were treated successfully (Table II).

Antibiotic therapy. Five out of six patients were treated with gentamicin for practically their entire course of medical therapy. The mean duration of therapy in these five patients was 94.4 days, (range: 36 to 171 days). The usual dosage was $4.5 \mathrm{mg}$. per kilogram per day in divided doses in patients with normal renal function. There was no good evidence of ototoxicity or renal toxicity from gentamicin in any of the patients. All five patients also received carbenicillin for most of the course of treatment in addition to gentamicin. The usual dosage of carbenicillin was 30 to $40 \mathrm{Gm}$. per day. Two patients received 
Table III. Antibiotic therapy and outcome in six patients with Pseudomonas endocarditis

\begin{tabular}{|c|c|c|c|c|c|c|}
\hline \multirow[b]{2}{*}{ Patient } & \multirow[b]{2}{*}{ Age } & \multirow[b]{2}{*}{ Sex } & \multirow[b]{2}{*}{$\begin{array}{l}\text { Valve } \\
\text { involved }\end{array}$} & \multicolumn{2}{|c|}{ Antibiotic therapy } & \multirow[b]{2}{*}{ Outcome } \\
\hline & & & & Drugs & $\begin{array}{l}\text { Total duration } \\
\quad \text { (days) }\end{array}$ & \\
\hline 1 & 29 & $\mathbf{M}$ & $\begin{array}{l}\text { Prosthetic } \\
\text { Aortic }\end{array}$ & $\begin{array}{l}\text { G, Carb } \\
\text { Colist }\end{array}$ & 21 & $\begin{array}{l}\text { Survived Pseudomonas and Flavobacterium } \\
\text { infections. Returned one month after } \\
\text { discharge and died of } S \text {. fecalis } \\
\text { endocarditis on prosthetic valve. }\end{array}$ \\
\hline 2 & 39 & $\mathbf{M}$ & Tricuspid & G, Carb & 39 & $\begin{array}{l}\text { Survived. Left hospital clinically well. } \\
\text { Never kept clinic appointment. }\end{array}$ \\
\hline 3 & 23 & $\mathbf{M}$ & Tricuspid & $\begin{array}{l}\text { G, Carb } \\
\text { PB }\end{array}$ & 158 & $\begin{array}{l}\text { Survived. Valve removed and no prosthesis } \\
\text { inserted. Died of unrelated causes one } \\
\text { year after treatment. }\end{array}$ \\
\hline 4 & 39 & $\mathbf{M}$ & Tricuspid & $\begin{array}{l}\text { G, Carb } \\
\text { Colist }\end{array}$ & 178 & $\begin{array}{l}\text { Died. Underwent surgery for ablation of } \\
\text { tricuspid valve. Never became conscious } \\
\text { post-op. Blood cultures remained positive } \\
\text { until death. }\end{array}$ \\
\hline 5 & 33 & F & $\begin{array}{l}\text { Prosthetic } \\
\text { tricuspid }\end{array}$ & G, Carb & 94 & $\begin{array}{l}\text { Survived. Prosthetic valve removed and not } \\
\text { replaced. Doing well with negative blood } \\
\text { cultures } 3 \text { months postoperatively. }\end{array}$ \\
\hline 6 & 45 & $\mathbf{M}$ & Tricuspid & Ceph & 6 & $\begin{array}{l}\text { Died on fifth hospital day. Blood culture } \\
\text { negative for Staphylococcus, but continued } \\
\text { positive for Pseudomonas. }\end{array}$ \\
\hline
\end{tabular}

$\mathrm{G}=$ gentamicin, Carb $=$ carbenicillin, Colist $=$ colistimethate, $\mathrm{PB}=$ polymixin $\mathrm{B}$, Ceph $=$ cephalothin.

colistimethate, $300 \mathrm{mg}$. per day. and one received polymixin $\mathrm{B}, 120 \mathrm{mg}$. per day, in combination with gentamicin and carbenicillin. The sixth patient was treated with cephalothin, $8 \mathrm{Gm}$. per day for $S$. aureus septicemia and died before appropriate therapy for Pseudomonas could be instituted (Table III).

The combination of carbenicillin and gentamicin was continued postoperatively in the three patients who went to surgery. The duration of postoperative antibiotic therapy was 20 days in the patient who died of continued septicemia and 28 days in each of the two patients who recovered and were cured of their infections.

The organisms isolated from the five patients who received gentamicin were sensitive to this drug by Kirby-Bauer disc sensitivity testing, and in two instances by serial dilution susceptibility studies. Susceptibility of the organisms was also demonstrated to both polymixin $B$ and colistimethate in the instances where these drugs were used. However, in all five cases where carbenicillin was used disc sensitivity testing showed variable susceptibility of isolates from individual patients at some time during therapy.

Results of therapy. Even though five patients were treated with appropriate antibiotics in adequate dosages for prolonged periods, only two pa- tients can be regarded as medical cures (Table III). One patient left the hospital apparently cured and another was cured of Pseudomonas infection, but blood cultures became positive for a different gram-negative rod, subsequently identified by the CDC as Flavobacterium meningisepticum. This organism was resistant to gentamicin, colistimethate, and polymixin B, antibiotics to which the Pseudomonas had been sensitive. The other three patients did not respond to extended courses of antibiotic therapy. Two of these three were eventually cured following surgical excision of the infected tricuspid valve.

Three of the six patients died. One of these was cured of Pseudomonas infection of his prosthetic valve but was later infected with Streptococcus fecalis and died of this infection. Another died without appropriate antibiotic therapy five days after admission and gram-negative rods were seen in the valve at autopsy. The third patient died after surgical removal of the valve, with continued positive blood cultures for Pseudomonas postoperatively. Infection of the valve as well as a myocardial abscess were found at surgery. Thus, of the three patients who survived, one was cured with medical therapy alone, while the other two required surgical removal of infected tricuspid valves because of refractory infection. All blood 
Table IV. Pathologic findings on valves at surgery or autopsy in six patients with Pseudomonas endocarditis

\begin{tabular}{|c|c|c|c|c|}
\hline Patient & Valve involved & Gross & Microscopic & Culture \\
\hline 1 & $\begin{array}{l}\text { Prosthetic } \\
\text { aortic }\end{array}$ & $\begin{array}{l}\text { Vegetations on } \\
\text { struts }\end{array}$ & $\begin{array}{l}\text { Gram-positive } \\
\text { cocci }\end{array}$ & S. fecalis \\
\hline 2 & Tricuspid & No specimen & No specimen & No specimen \\
\hline 3 & Tricuspid & $\begin{array}{l}\text { Valve friable } \\
\text { and thickened }\end{array}$ & $\begin{array}{l}\text { Chronic inflammation } \\
\text { No organisms seen }\end{array}$ & $\begin{array}{l}\text { Valve negative, but left } \\
\text { atrial blood culture } \\
\text { positive for } P \text {. aeruginosa }\end{array}$ \\
\hline 4 & Tricuspid & $\begin{array}{l}\text { Leaflets sclerotic } \\
\text { and thickened with } \\
\text { firm vegetations }\end{array}$ & $\begin{array}{l}\text { Covered with } \\
\text { fibrinous exudate. } \\
\text { No organisms seen }\end{array}$ & P. aeruginosa \\
\hline 5 & $\begin{array}{r}\text { Prosthetic } \\
\text { tricuspid }\end{array}$ & $\begin{array}{l}\text { Vegetations on } \\
\text { struts }\end{array}$ & Not done & P. aeruginosa \\
\hline 6 & Tricuspid & Acute valvulitis & $\begin{array}{l}\text { Necrotizing arteritis } \\
\text { and myocoarditis; } \\
\text { gram-negative rods. }\end{array}$ & Not done \\
\hline
\end{tabular}

cultures remained negative after surgery in the latter two patients who were continued on antibiotics. These two patients were free from infection, had minimal signs of congestive heart failure, and had returned to work when seen three months postoperatively. They have been lost to follow-up since that time.

The mean duration of hospitalization was 3.8 months, with the shortest seven days and the longest eight months. None of the three patients who survived has returned for more than one out-patient follow-up visit.

Pathologic data. There were five patients from whom tissue from the involved valve was obtained for examination (Table IV). $P$. aeruginosa was cultured from two patients, and gram-negative rods were seen in the valve of a third patient whose postmortem heart blood culture grew the organism. A fourth patient presumably had his valve sterilized of Pseudomonas by antibiotic therapy, and died of endocarditis due to $S$. fecalis. A fifth patient ceased having positive blood cultures after the removal of a chronically inflamed valve, although the section of valve cultured was sterile.

\section{Illustrative cases}

Patient No. 1, a 29-year-old male, was a known heroin addict who was admitted to the Wayne County General Hospital on Oct. 30, 1971. A diagnosis of acute Staphylococcal endocarditis of the aortic valve was made and antibiotic therapy was instituted. A ruptured aortic valve cusp necessitated urgent replacement of the valve with a
Starr-Edwards prosthesis. It was strongly suspected that he continued the intravenous use of narcotics while in the hospital. He was discharged in Jan. 1972. On April 15, 1972, he returned with fever, chills, and night sweats, and admitted to continued heroin abuse. He had loud systolic murmurs over his entire precordium, splenomegaly, splinter hemorrhages, and gross hematuria. Blood cultures were positive for $P$. aeruginosa, and therapy was begun with gentamicin and carbenicillin. Eventually, colistimethate was added, but he continued to be febrile with positive blood cultures. He had an intermittent diastolic murmur that changed with respiration and bounding jugular venous pulses, and it was uncertain whether his endocarditis involved the tricuspid valve, the aortic prosthesis, or both. Cardiac catheterization with cineangiography was performed, and revealed no dysfunction of the tricuspid valve. Quantitative blood cultures obtained from both the right and left side of the heart at the time of catheterization suggested that the prosthetic valve was the focus of infection. There were 35 colony-forming units per milliliter of blood in the ascending aorta, but only 6 per milliliter in right ventricular blood. The organism isolated during this procedure was found later not to be the original $P$. aeruginosa, and was identified by the CDC as $F$. meningisepticum, resistant to all antibiotics but clindamycin, rifampicin, and vancomycin. He refused surgical replacement of his prosthetic valve and therapy with these three antibiotics was begun. After three months of treatment, his 
blood cultures became negative and he was discharged clinically well on Sept. 9, 1972. He returned on Oct. 21, 1972, with blood cultures positive for $S$. fecalis and died soon thereafter of cerebral emboli. Cultures of posthetic valve vegetations at autopsy were positive only for $S$. fecalis. The tricuspid valve appeared normal.

Comment. This remarkable patient had endocarditis with four different pathogens in ten months. He survived the first three and died of the fourth, caused by $S$. fecalis. The last three infections were all on his prosthetic valve. This illustrates the futility of inserting prosthetic valves into drug addicts who are continuing to use intravenous narcotics, and also suggests the usefulness of quantitative blood cultures in conjunction with cardiac catheterization as a means of localizing the infected valve. This is of particular importance with Pseudomonas endocarditis because the infection is often refractory to antibiotic therapy, and surgical removal of the valve may be the only means of eradicating the site of infection. Since addicts can infect one or several valves not known to have been previously deformed, clinical localization prior to surgery is often difficult.

Patient No. 2, a 38-year-old male, was a chronic narcotics abuser, including intravenous injection of heroin, paregoric, and cocaine. Two months prior to admission he noted the onset of fever, night sweats, bilateral pleuritic chest pain, anorexia, fatigue, and dyspnea. He presented on April 19, 1972, with a temperature of $103^{\circ} \mathrm{F}$., tachypnea, disabling chest pain, and a 20-pound weight loss. Physical examination revealed a characteristic murmur of tricuspid insufficiency, splenomegaly, and scars of intravenous drug administration on his forearms. Blood gases revealed severe hypoxemia and a chest $\mathrm{x}$-ray showed multiple scattered infiltrates. Multiple blood cultures grew $P$. aeruginosa, and therapy was begun with intravenous carbenicillin and gentamicin. The presumptive diagnosis was tricuspid valvulitis and septic pulmonary embolization. Five days after therapy was begun he had sudden severe chest pain, dyspnea, and a pleural rub. He gradually improved and became afebrile on May 3, 1972. Blood cultures on four occasions during therapy were negative. Infiltrates on the chest $x$-ray cavitated and slowly resolved. Antibiotics were discontinued on May 30, 1972, after six weeks of treatment, and the patient was clini- cally well. Two of six blood cultures taken when antibiotics were discontinued were positive for Pseudomonas, but seven subsequent blood cultures obtained over the next-week were negative. He was discharged on June 13, 1972. He was not suspected of using narcotics while in the hospital. He never kept follow-up appointments. One of his friends reported to us that he was alive in early 1973 , but his medical status is otherwise unknown.

Comment. This patient probably represents a cure with antibiotics alone. It is possible that his two positive blood cultures after treatment were the result of surreptitious intravenous drug use.

Patient No. 3, a 23-year-old man, was an addict who admitted to almost daily intravenous injections. He presented on Nov. 17, 1970, with a oneweek history of hemoptysis, malaise, fever, chills, anorexia, and left-sided pleuritic chest pain. There were râles, decreased breath sounds, and a friction rub at the left base. Thrombophlebitis and cellulitis of the right arm and obvious needle marks were present. Splenomegaly, splinter hemorrhages, petechiae, hematuria, and cardiac murmurs were not found. Sputum culture grew Diplococcus pneumoniae, and chest $\mathrm{x}$-ray showed a left lower lobe infiltrate with effusion. Cultures from the right arm and blood grew Group A betahemolytic Streptococci. Therapy was begun with intravenous penicillin, four million units per day. Blood cultures repeated on Nov. 22 were reported on Nov. 24 as growing $P$. aeruginosa in all four bottles, and intravenous carbenicillin was added to penicillin. He became afebrile and he felt well. On Dec. 5, after eleven days of carbenicillin and eighteen days of intravenous penicillin, all antibiotics were discontinued. A cardiac focus of Pseudomonas septicemia was not suspected. Additional blood cultures were obtained on Dec. 8 , but he was discharged, receiving oral phenoxymethylpenicillin. On Dec. 16, one of two blood cultures was growing $P$. aeruginosa, but attempts to recall him for further treatment were unsuccessful.

On Feb. 24, 1971, he presented to the hospital with several weeks of weakness, shortness of breath, chills, fever, pleuritic chest pain, and hemoptysis. On physical examination he was febrile and tachypneic with rales and a pleural rub at the right base. A loud murmur characteristic of tricuspid insufficiency was heard at the lower sternal border. Jugular veins were distended and 
bounding and splenomegaly was present, but there were no splinters or petechiae. Chest $\mathrm{x}$-ray revealed patchy bilateral infiltrates and a cavity in the right midlung field. All eight blood cultures from admission grew $P$. aeruginosa, and therapy was begun with intravenous cephalothin and intramuscular gentamicin. He continued to be febrile, blood cultures remained positive, and pleuritic chest pain became more severe. Carbenicillin was substituted for cephalothin when the nature of the organism was known, but carbenicillin and gentamicin, carbenicillin alone, and carbenicillin with gentamicin and polymixin $B$ failed to decrease symptoms or sterilize the blood. After four months of failure of intensive medical therapy, he was taken to the operating room on June 23,1971 . A very friable and thickened tricuspid valve was removed, and no prosthesis was inserted. Culture of the left atrial blood at surgery yielded $P$. aeruginosa, but the portion of valve cultured was sterile. He did well postoperatively, with no recurrence of chest pain, and with increased appetite, weight gain, and negative blood cultures. He was discharged and was doing well one month later when he returned for his first follow-up visit. He was lost to follow-up for nine months and died on July 22, 1972 , of a gunshot wound to the abdomen.

Comment. One possible explanation for failure of therapy in this man was late treatment because of the failure to diagnose endocarditis when it first presented. The bacteremia was not felt to originate from the heart, in spite of lack of good evidence to support other sites, and he was treated with only a short course of carbenicillin. By the time definitive therapy was instituted, endocarditis was well established. Since four months of bactericidal antibiotic therapy did not cure the infection, surgery was required and appeared curative.

\section{Discussion}

Bacterial endocarditis caused by $P$. aeruginosa was an extremely rare disease prior to 1960 , with only 32 reported cases. ${ }^{4,5}$ These consisted of nine patients who had infection of presumably normal valves, eleven patients with previous valve damage secondary to rheumatic heart disease, and seven patients with infection of an intracardiac foreign body following cardiac surgery. Since 1960, wht spectrum of disease has changed so that virtually all of the cases have been seen either following cardiac surgery ${ }^{6.9}$ or in drug addicts. The organism is now recognized as a com. mon contaminant of hospital equipment and a potential source of infection of intracardiac foreign bodies. ${ }^{10}$ However, only recently has Pseudomonas endocarditis in the narcotic user reached serious proportions. Reyes and coworkers ${ }^{11}$ recently reported 21 cases of Pseudomonas endocarditis in heroin addicts seen at the Detroit General Hospital. Our findings confirm teirs and support their conclusions. Their cases, together with our six patients, are in contrast to only 13 cases of Pseudomonas endocarditis out of a total of 273 cases of endocarditis in drug users gleaned from the literature. ${ }^{4}$, ${ }^{12-18}$ All of our patients, and those patients reported by Reyes, have been seen since 1969, and are drawn from the same geographic area.

Several features in our patients are similar to those reported by Reyes. The tricuspid valve was involved in five of six (83 per cent) of our patients and in 16 of 21 (76 per cent) of Reyes' patients. The increased frequency of tricuspid endocarditis among addicts as compared to specifically matched controls among the nonaddict endocarditis population has been noted by Cherubin and co-workers. ${ }^{16}$ However, they found no organism predilection for a particular valve in addicts as compared with control subjects.

Two (33 per cent) of our patients were cured by medical therapy alone, which is similar to Reyes' experience ( 24 per cent). All of the patients in our series (one) and five out of six patients in Reyes' series with infection of the left side of the heart died. Seven out of 21 (33 per cent of the combined series of tricuspid valve infections responded to intensive antibiotic treatment. Thus, although infection of the tricuspid valve seemed to offer a better prognosis than left-sided endocarditis, two-thirds of the patients with tricuspid endocarditis did not respond to antibiotic therapy alone.

Surgery was eventually required for removal of the infected focus in three of our six patients (50 per cent), and in 12 out of 21 of Reyes' patients ( 57 per cent). All had failed to respond to prolonged courses of antibiotics. Three of Reyes' patients underwent surgery with insertion of a prosthesis, and another had an attempted excision of a left atrial focus of infection. These four patients died of continued infection. All three of our surgical patients and the remaining eight of 
Reyes' patients had removal of the tricuspid valve without insertion of a prosthesis. Eight (73 per cent) of these patients survived and were free of infection when last seen. We treated our patients for one month with appropriate antibiotics postoperatively.

There is little to offer the addict with left-sided Pseudomonas endocarditis who does not respond to medical therapy. Reinfection of inserted prostheses has been very frequent ampng drug users, as observed in Reyes' patients and in ours. However, total ablation of the tricuspid valve is well tolerated and offers an excellent opportunity for salvaging the patient with an infected tricuspid valve who has not responded to conventional therapy. ${ }^{17}$

Antibiotic therapy with a combination of gentamicin and carbenicillin was used in five out of six ( 83 per cent) of our patients and in 17 out of 21 ( 81 per cent) of Reyes' patients. In neither series could the success of medical therapy alone be predicted on the basis of drug dosage, duration of therapy, or in vitro antibiotic susceptibility. In our study, variable resistance and sensitivity of the same organism to carbenicillin, as tested by the disc sensitivity method, was noted in all patients. There is evidence that some organisms found resistant by use of the standard 50 microgram carbenicillin disc currently recommended by the Food and Drug Administration (FDA) may be found to be susceptible by the serial broth dilution method (susceptibility defined as a minimal inhibitory concentration of equal to or less than 100 micrograms per milliliter). The use of a 100 microgram disc is reported to markedly reduce the discrepancies between the two susceptibility testing methods. ${ }^{18}$ In Reyes' series, organisms from five out of six patients who responded to medical therapy alone had a minimal inhibitory concentration of 100 micrograms per milliliter or greater as determined by the serial broth dilution method. These organisms would have been determined resistant by the disc diffusion method, using even the 100 microgram disc. Thus, the correlation between in vitro testing and in the vivo efficacy of carbenicillin in treating Pseudomonas endocarditis is unclear. There may be in vivo synergism between carbenicillin and gentamicin to explain the apparent efficacy of this combination in treating some of the patients. ${ }^{19}$

The clinical presentation, physical findings, and course of the illnesses were similar in the majority of the cases in both series. The typical patient was a black male heroin addict under forty years of age who presented with a history of several weeks or months of malaise, anorexia, and weight loss. The symptoms were more suggestive of subacute than acute bacterial endocarditis. Chest pain or chills were usually responsible for the patient seeking medical help. On physical examination, fever was invariably present but vital signs were otherwise normal. A murmur of tricuspid insufficiency was usually present, but meticulous auscultation was required because these murmurs were soft and changeable. Banks, Fletcher, and Nayab ${ }^{14}$ have recently reported on 50 patients with heroin associated endocarditis, 42 of whom had tricuspid involvement. In 16 of these 42 patients with tricuspid regurgitation, the tricuspid murmur was not present or not recognized at the time of admission. In two patients, an atrial diastolic gallop, a ventricular diastolic gallop, or a systolic click, heard over the left lower sternal border and external jugular vein, preceded the late appearance of typical murmurs of tricuspid insufficiency.

Cardiac catheterization may be necessary to delineate valvular dysfunction in some patients with minimal auscultatory signs, particularly if cardiac surgery is contemplated. If catheterization is performed, quantitative blood cultures from both the right and left sides of the heart may be an additional method of localizing the site of infection to a particular valve. This is exemplified by one of our patients (Patient No. 1) in whom quantitative blood cultures suggested that the prosthetic aortic valve and not the tricuspid valve was infected. This was confirmed at autopsy.

Splenomegaly was common in our series (Table I) but uncommon in Reyes' series. Peripheral manifestations of endocarditis, such as petechiae, Roth's spots, and hematuria were rarely seen. Scars produced by multiple intravenous infections were usually found when diligently sought. The white blood cell count was not often helpful. Although it was often above 10,000 per cubic millimeter, there was frequently no increase in the percentage of neutrophils or band forms. Chest $\mathrm{x}$-rays showed multiple infiltrates, frequently but not always cavitary, which represented septic emboli. These were not present 
when the left side of the heart alone was involved. There was usually no radiologic evidence of cardiomegaly or congestive heart failure. If the patient had received no prior antibiotic therapy, all blood cultures usually grew the organism. Cultures could remain positive for prolonged periods during treatment before eventual bacteriologic conversion. It was remarkable how well the patient felt while continuously bacteremic. Variations in the typical presentation of Pseudomonas endocarditis occurred where there was a mixed infection with $S$. aureus. In such cases, the patient often presented with fulminant acute bacterial endocarditis. There was nothing about the clinical presentation of Pseudomonas endocarditis that distinguished it from endocarditis due to other pathogens of intermediate virulence. However, it is important to recognize that the recovery of $P$. aeruginosa from blood cultures in a drug user who does not appear very ill might represent endocarditis.

Two of our patients had infection of prosthetic valves. These valves had been inserted because of valve destruction secondary to bacterial endocarditis. Presumably, the organisms were originally introduced with intravenous narcotic injection. The subsequent infection of the prosthesis was felt likely to be due to organisms injected during intravenous drug use and not to contamination at the time of surgery, because blood cultures became positive four and six months after surgery and both patients admitted heavy use of drugs in the interim.

The pathogenesis of Pseudomonas endocarditis remains obscure. Infection of heart valves with gram-negative organisms is unusual and infection of undamaged valves by them is exceedingly rare. The organisms are undoubtedly injected intravenously as contaminants of the narcotic preparation, syringe, or diluent, although attempts to recover the organism from these sources have not been very rewarding. ${ }^{11} P$. aeruginosa is a hardy organism, surviving in such common moist locations as sinks, drains, taps, and soaps. ${ }^{10}$ This is particularly true in hospitals, where the incidence of nosocomial infections with this organism is high. The increasing incidence of endocarditis with this organism suggests that medical facilities may be a source of the implicated syringes, fillers, or diluents. However, frequent or continuous bacteremia with Pseudomonas in severely burned patients is com. mon but rarely results in endocarditis. ${ }^{20,21}$ Thus, there seems to be some predisposing factor in narcotic addicts which makes them more susceptible to endocarditis with this organism. Such things as changes in hemodynamics in the right side of the heart resulting in turbulent flow or the quantity and frequency of injection of the bacteria are possible contributory factors.

Both Angrist and $\mathrm{Oka}^{24}$ and Durack and Beeson ${ }^{25}$ have proposed that infection of heart valves with organisms of low virulence is dependent on previous disruption of the endothelial surface of the valve. A sterile vegetation or roughened valve surface is produced and is then colonized by bacteria at the time of bacteremia. In the narcotic addict there are several possible mechanisms of such valve damage. Some materials used to cut the narcotic, such as talc or starch, are particulate and could cause damage to the surface of the tricuspid valve. Another possibility is that bacteremia with more virulent organisms could damage the valve. Such organisms may co-exist with Pseudomonas in a polymicrobial infection. If a virulent organism, such as $S$. aureus, is not present in large numbers it may be supplanted on the valve surface by Pseudomonas. This is particularly true if antibiotics are administered by the patient or a local physician, suppressing the original pathogen and allowing Pseudomonas to flourish. Rabin and coworkers $^{23}$ reported three cases of Pseudomonas endocarditis in burned patients following Pseudomonas septicemia. In all three cases, the Pseudomonas septicemia had followed prolonged Staphylococcal septicemia, or was coincident with it. In one case, both $P$. aeruginosa and $S$. aureus were recovered from an aortic vegetation at postmortem examination. In four of the 21 narcotics users in Reyes' series, both $P$. aeruginosa and $S$. aureus were recovered from the blood at some time during hospitalization. In three of our patients, organisms known to cause damage to normal heart valves were isolated from the blood on admission to the hospital. Group A beta-hemolytic Streptococcus, S. fecalis, and $S$. aureus were grown from the blood one to thirteen days before the first culture became positive for Pseudomonas. Since two other patients in our series had their infection on prosthetic valves, there remains only one patient with normal valves who had Pseudomonas as the sole organism isolated from blood cultures. 
The financial drain on society that the addict represents is exemplified by our patients. The stubborn and refractory illness leading to prolonged hospitalization in five of the six patients produced an average hospital bill of $\$ 31,000$, with a range of $\$ 7,000$ to $\$ 42,000$.

\section{Summary}

Six intravenous heroin users with $P$. endocarditis were seen between 1970 and 1972 . Five out of six ( 83 per cent) had tricuspid valvulitis. Fever and a significant murmur were found in all cases, a subacute presentation and splenomegaly were found in 83 per cent, and chest pain with cavitating infiltrates on x-ray was observed in 67 per cent. Three patients died of infection. Three patients survived; one was cured with medical therapy alone, and two required surgical removal of the infected valve as well. The success of surgical ablation of the tricuspid valve in these patients is encouraging, particularly in view of their poor response before surgery to combinations of antibiotics with proved in vitro efficacy. Prior bacteremia with more virulent organisms may be important in the pathogenesis of endocarditis with Pseudomonas.

\section{REFERENCES}

1. Bailey, W. R., and Scott, E. G.: Diagnostic microbiology, Ed. 3, St. Louis, 1970, The C. V. Mosby Company, p. 161.

2. Bauer, A. W., Kirby, W. M. M., Sherris, J. C., and Turck, M.: Antibiotic susceptibility testing by a standardized single disc method, Am. J. Clin. Pathol. 45:493, 1966.

3. Harwick, H. J., Weiss, P., and Fekety, F. R.: Application of microtitration techniques to bacteriostatic and bactericidal antibiotic susceptibility testing, J. Lab. Clin. Med. 72:511, 1968.

4. Saroff, A. L., Armstrong, D., and Johnson, W. D.: Pseudomonas endocarditis, Am. J. Cardiol. 32:234, 1973.

5. Hills, H. F.: A case of puerperal septicemia due to Pseudomonas pyocyanea with a short review of the literature, J. Obstet. Gynaecol. Br. Emp. 56:860, 1949.

6. Littlefield, J. B., Muller, W. H., and Dammann, J. F.: Successful treatment of Pseudomonas aeruginosa septicemia following total aortic valve replacement, Circulation (Suppl. 1) 31:I, 1965.

7. Yeh, T. J., Anabtaw, I. N. Cornett, V. E., White, A.,
Stern, W. H., and Ellison, R. G.: Bacterial endocarditis following open-heart surgery, Ann. Thorac. Surg. 3:29, 1967.

8. Firor, W. B.: Infection following open-heart surgery with special reference to the role of prophylactic antibiotics, J. Thorac. Cardiovasc. Surg. 53:371, 1967.

9. Block, P. C., DeSanctis, R. W. Weinberg, A. N., and Austen, W. G.: Prosthetic valve endocarditis, J. Thorac. Cardiovasc. Surg. 60:540, 1970.

10. Whitby, J. L., and Rampling, A.: Pseudomonas aeruginosa contamination in domestic and hospital environments, Lancet 1:15, 1972.

11. Reyes, M.P., Palutke, W. A., Wylin, R.F., and Lerner, A. M.: Pseudomonas endocarditis in the Detroit Medical Center, 1969-1972, Medicine 52:173, 1973.

12. Ramsey, R. G., Gunnar, P. M., and Tobin, J. R.: Endocarditis in the drug addict, Am. J. Cardiol. 25:608, 1970.

13. Dreyer, N. P., and Fields, B. N.: Heroin-associated infective endocarditis, a report of 28 cases, Ann. Intern. Med. 78:699, 1973.

14. Banks, T., Fletcher R., and Nayab, A.: Infective endocarditis in heroin addicts, Am. J. Med. 65:444, 1973.

15. Menda, K. B., and Gorbach, S. L: Favorable experience with bacterial endocarditis in heroin addicts, Ann. Intern. Med. 78:25, 1973.

16. Cherubin, C. E., Baden, M., Kavalier, F., Lerner, S., and Cline, W.: Infective endocarditis in narcotic addicts, Ann. Intern. Med. 69:1091, 1968.

17. Graham, D. Y., Reul, G. J., Martin, R., Morton, J., and Kennedy, J. H.: Infective endocarditis in drug addicts: experiences with medical and surgical treatment, $\mathrm{Cir}$ culation 47 and 48 (Suppl. III):III, 1973.

18. Carrathers, M. M., and Kanokvechayant, R.: Pseudomonas aeruginosa endocarditis : report of a case, with review of the literature, Am. J. Med. 55:811, 1973.

19. Arbulu, A., Thomas, N. W., and Wilson, R. F.: Valvulectomy without prosthetic replacement, a livesaving operation for tricuspid Pseudomonas endocarditis, J. Thorac. Cardiovasc. Surg. 64:103, 1972.

20. Washington, J. A., Hall, M. M., Fausch, C. J., and Brackin, K. L.: In vitro activity of carbenicillin against Pseudomonas using the disc diffusion method, Mayo Clin. Proc. 48:718, 1973.

21. Andriole, V. T.: Synergy of carbenicillin and gentamicin in experimental infection with Pseudomonas, J. Infect. Dis. 124(Suppl.):S46, 1971.

22. Stone, H. H.: A review of Pseudomonas sepsis in thermal burns. Verdoglobin determination of gentamicin therapy. Ann. Surg. 163:297, 1966.

23. Rabin, E., Garber, C. D., Vogel, E. H., Finkelstein, R. A., and Tumbusch, W. A.: Fatal Pseudomonas infection in burned patients, N. Engl. J. Med. 265:1225, 1961.

24. Angrist, A., and Oka, M.: Pathogenesis of bacterial endocarditis, J. A. M. A. 183:249, 1963.

25. Durack, D. T., and Beeson, P. B.: Experimental bacterial endocarditis. I. Colonization of sterile vegetation, Br. J. Exp. Pathol. 53:44, 1972. 